\title{
Where have all the medicines gone?
}

\section{Steve Tomlin}

"The test of morality of a society is what it does for its children" is a famous quote from the German philosopher, Dietrich Bonhoeffer. Yet we struggle to deliver appropriate medicines to our children on so many levels. With a lack of studies being performed on both the medicines and the formulations that we are using, it is a wonder that we ever have any good treatment outcomes. How is it possible then, that when we do have treatments that can be used almost overnight the medicine that we were using can just disappear from the market?

The situation was highlighted in 2012 in the USA when Jennifer LaCognata tried to sue Hospira for removing Vitamin A injections from the market. She had started to have night blindness and was relieved to find there was a simple treatment in the form of an injection. Soon after starting treatment, Hospira ceased manufacture and there was a worldwide shortage. With no alternative product in place, her sight deteriorated and she became blind in one eye and began to lose her sight in the other. She lost the case as it was judged that the medicines industry has no duty to ensure continuity of supply. This story and others like it moved the US government to allow the Food and Drug Administration more power to try to prevent shortages. While these moves have only been partially successful, they are still better than the lack of control we have in Europe. The European Medicines Agency (EMA) approves medicines but has only very limited strategies in place to address shortages. There is no coordinated approach to shortages in place and industry is not even obliged to inform the EMA if they know that a shortage is likely.

So when we are looking at the complex issue of selecting medicines for children; there is now a need to add continuity of supply to the established list of being effective, safe and cost effective. A survey in 2014 by the European Association of Hospital Pharmacists (EAHP) showed that of over 500 pharmacies in 36 European countries, half said they were affected by shortages every week. ${ }^{1}$ Additionally, community pharmacists report spending the

Correspondence to Mr Steve Tomlin, Department of Pharmacy, Guys St Thomas@NHS Foundation trust, Evelina Childrens Hospital, London SE1 7EH, UK; stephen.tomlin@gstt.nhs.uk equivalent of two full working days a month phoning manufacturers and suppliers trying to source out-of-stock medicines. The same survey concluded that around 700000 patients in the UK are affected each year due to issues in the medicine supply chain. ${ }^{2}$ This could be seen as a drop in the ocean against the two million prescriptions dispensed from English community pharmacies every day. However, with between 30 and 50 medicines being in short supply at any time, ${ }^{3}$ this is a real problem, having a significant impact on both the adult and paediatric populations across the UK.

There are many reasons why drug shortages occur. The underlying reasons are often related to the manufacturing systems and quality issues, but are also related to product discontinuation, sourcing of raw materials and, of course, commercial considerations. With a pharmaceutical industry now operating in a global market, it is easy to see how it becomes more efficient to concentrate manufacture on one site and have supply systems based on satisfying immediate need rather than ensuring continuity of supply. It only takes one thing to go wrong in the system for a supply issue to quickly hit clinical practice. This issue is already being discussed on a national level to address concerns about the provision of parenteral nutrition (PN) in paediatrics. In early 2015, there was a quality issue with one of the large PN suppliers in the UK; thankfully production was allowed to continue as it was realised that there are no longer enough large centres in the UK capable of supplying the market if that company stops production. The supply chain for medicines to treat rare disease treatments is perhaps even more vulnerable. Only recently there was a move from one centre to cease manufacture due to quality issues. However, they are the only supplier of copper histidine (a life-saving treatment in Menkes disease) in the UK and as yet permission to import has not been granted.

While there are occasional natural disasters that affect the pharmaceutical industry's ability to manufacture medicines, a company may also just decide to cease production. This may be due to production unit problems or inability to obtain the raw materials; however, it may just be that it is not seen as financially viable to continue. If that company is the only manufacturer, then the implications will be seen very quickly. However, even where there are other manufacturers, the process often destabilises the market, as the alternative manufacturers trying to meet demand and supply may come and go over a period of time, as the market tries to adapt.

The reason for 'out of stock' that is hardest to stomach, from the clinical perspective, is where the shortage is purely due to financial trading that results in medicine supplies for children becoming unavailable. The medicines industry is vast, highly competitive and works internationally. There are two main ways of trading that may cause medicine shortages. The first is to actually create a shortage by stockpiling medicines (the so-called grey market), allowing them to increase the prices that buyers are willing to pay. ${ }^{4}$ The second trading option applies to branded medicines and is known as 'parallel exporting'. 5 Drugs in the UK market are often relatively cheap and a wholesaler dealer can sell them for a higher price in the European markets. This creates an issue where there should have been enough of the medicine for the UK market, but it has been sold outside of the country. This has now been limited by putting quotas for the use of medicines in the UK and limiting the wholesaler dealing. In 2012, the All Party Pharmacy Group stated that parallel exporting was 'a major cause of brand medicine shortage' and asked for a change in EU law in order to protect UK patients, but this has never happened.

Out-of-stock medicines are not only an issue due to the inability to use the product of choice in a particular clinical scenario, but also create safety issues for ongoing practice.

The disappearance of Organon's Dexamethasone $4 \mathrm{mg} / \mathrm{mL}$ injection from the market created chaos for practice as, not only did the alternatives all have different volumes and concentrations of dexamethasone in a vial, they also had the concentrations explained in terms of different salts (base, sodium phosphate, phosphate). With clinicians remembering a $\mathrm{mg} / \mathrm{kg}$ dose, it soon became clear that the certainty that children would be prescribed the dose required greatly diminished.

Calcium-Sandoz syrup was removed from the UK market in 2013 with no other calcium liquid formulations on the market. The immediate move was to use the effervescent tablets (Sandocal and Calcit). However, both tablets when 
dissolved in water have a displacement volume (the final volume of liquid is greater than the water you put the tablet in) and the displacements seem variablenot ideal when most children will only be having a small proportion of each dispersed tablet and very complicated for parents to administer. There is an oral liquid calcium food supplement now on the market, but do we really want to promote use of medicines which have not gone through the medicines regulatory process and whose content is likely to be far more variable?

While all these issues are important to adults and children, it is generally more complicated to source a suitable alternative for the paediatric market as there are less medicines appropriate for use in the first place. We also have to consider the use of unlicensed medicines. There is even less assurance of continuity of supply of these products and certainly less communication, irrespective of whether it is a special or an import. While it may be relatively easy to find another supplier, it is worth bearing in mind that few specials have any bioequivalence data and thus swapping between specials may produce a completely different drug level and contain different active excipients, increasing the need for more vigilance and monitoring.

So to answer 'where have all the medicines gone' is no simple matter and is a problem that is applicable to branded, generic and unlicensed medicines. With a limited access to appropriate medicines and formulations in place with children generally, this is just an additional problem to work through as we try to deliver appropriate care. While national groups are listening and aware of the issues, the changes made so far have been slow to deliver improvement. Nevertheless it is essential that professional groups politically lobby on behalf of their profession and the children for which they care. It is essential that the EMA takes on the burden of implementing controls to avoid the shortage problems. Good communication and strong multidisciplinary working will have to continue to prevail to ensure we supply the best medicines possible for our children.
Competing interests None declared.

Provenance and peer review Commissioned; externally peer reviewed.

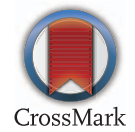

To cite Tomlin S. Arch Dis Child 2016;101:648-649.

Received 19 October 2015

Revised 18 January 2016

Accepted 21 January 2016

Published Online First 12 February 2016

Arch Dis Child 2016:101:648-649.

doi:10.1136/archdischild-2014-307907

\section{REFERENCES}

1 European Association of Hospital Pharmacists Medicines Shortages in European Hospitals. The Evidence and Case for Action. 2014.

2 Chemist and Druggist. Medicines shortages report. 2013.

3 National Pharmacy Association. Medicines Shortages, March to December 2014. 2014. http://www.npa.co.uk

4 Liang BA, Mackey TK. Online availability and safety of drugs in shortage: a descriptive study on internet vendor characteristics. J Med Internet Res 2012; 14:e27.

5 All Party Pharmacy Group. Report of APPG inquiry into medicines shortages. 2012. http://www.appg.org.uk 